\title{
Can oceanic paleothermometers reconstruct the Atlantic Multidecadal Oscillation?
}

\author{
D. Heslop ${ }^{1, *}$ and A. Paul ${ }^{2}$ \\ ${ }^{1}$ Department of Geosciences, University of Bremen, 28334 Bremen, Germany \\ ${ }^{2}$ MARUM - Center for Marine Environmental Sciences, University Bremen, 28334 Bremen, Germany \\ *now at: Research School of Earth Sciences, The Australian National University, Canberra ACT 0200, Australia
}

Received: 15 September 2010 - Published in Clim. Past Discuss.: 14 October 2010

Revised: 28 January 2011 - Accepted: 30 January 2011 - Published: 2 March 2011

\begin{abstract}
Instrumental records of the North Atlantic sea surface temperature reveal a large-scale low frequency mode of variability that has become known as the Atlantic Multidecadal Oscillation (AMO). Proxy and modelling studies have demonstrated the important consequences of the AMO on other components of the climate system both within and outside the Atlantic region. Over longer time scales, the past behavior of the AMO is predominantly constrained by terrestrial proxies and only a limited number of records are available from the marine realm itself. Here we use an Earth System-Climate Model of intermediate complexity to simulate AMO-type behavior in the Atlantic with a specific focus placed on the ability of ocean paleothermometers to capture the associated surface and subsurface temperature variability. Given their lower prediction errors and annual resolution, coral-based proxies of sea surface temperature appear to be capable of reconstructing the temperature variations associated with the past AMO with an adequate signal-to-noise ratio. In contrast, the relatively high prediction error and low temporal resolution of sediment-based proxies, such as the composition of foraminiferal calcite, limits their ability to produce interpretable records of past temperature anomalies corresponding to AMO activity. Whilst the presented results will inevitably be model-dependent to some degree, the statistical framework is model-independent and can be applied to a wide variety of scenarios.
\end{abstract}

\section{Introduction}

The Atlantic Multidecadal Oscillation (AMO) is a leading mode of sea surface temperature (SST) variability with a period of 30-80 years (Delworth and Mann, 2000). The SST

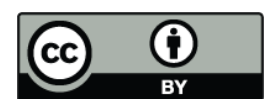

Correspondence to: D. Heslop

(dheslop@uni-bremen.de) pattern attributed to the AMO plays an important role in modulating key components of the climate system, for example, the African and Indian summer monsoons, North American and European summer climate, and the activity of hurricanes in the Atlantic (Sutton and Hodson, 2005; Zhang and Delworth, 2006; Shanahan et al., 2009). Therefore, understanding the evolution of the AMO and its variability through time is of key importance.

The AMO was first identified and characterized on the basis of instrumental temperature records spanning the last $\sim 150$ years (Mann and Park, 1994; Schlesinger and Ramankutty, 1994). Subsequently, a focus has been placed on exploring the spectrum of AMO variability more fully via the quantification of past spatial and temporal evolution of temperature anomalies using calibrated proxies (Delworth and Mann, 2000; Gray et al., 2004; Saenger et al., 2009).

Proxy reconstruction efforts have been complemented by a variety of modelling experiments, ranging from atmosphereonly models forced to mimic the AMO (Sutton and Hodson, 2005), to fully coupled models that exhibit spontaneous AMO-type variability (Knight et al., 2005). The specific forcing mechanism of the AMO is still a matter of debate. However, modelling studies do provide strong support for an active role of the Atlantic Meridional Overturning Circulation (AMOC), at least partially, driving the development of the SST patterns that characterize the AMO (for a review see Delworth et al., 2007).

The currently available proxy reconstructions of the AMO have mainly relied on dendroclimatological networks, in which high resolution (annual) records with precise chronologies are available (Delworth and Mann, 2000; Gray et al., 2004). However, given the hypothesized link between the AMO and AMOC it is desirable to attempt to reconstruct past AMO activity directly from marine archives (Saenger et al., 2009). Corals have the potential to provide absolutely dated and annual (or sub-annual) resolution reconstructions of SST, but their availability is limited and

Published by Copernicus Publications on behalf of the European Geosciences Union. 
often the duration of the records is not sufficient to isolate the AMO component (Kuhnert et al., 2002; Kilbourne et al., 2008; Saenger et al., 2009). In contrast, temperature reconstructions derived from sediment archives, for example based on the composition of foraminiferal calcite (Lea, 1999), have a lower temporal resolution but are capable of spanning much longer periods than coral records. The limiting factors for sedimentary records are their accumulation rate and processes such as bioturbation, both of which act to smooth the recorded temperature signal. Recent sediment-based studies have achieved resolutions that have allowed the examination of interannual and subdecadal modes (Black et al., 2007; Sicre et al., 2008). However, such records are generally only available in special settings such as marginal basins and not the open ocean.

Here we have performed a feasibility study to determine with what fidelity past AMO-type behavior can be reconstructed based on the calibrated proxies of seawater temperature. We have employed a climate model that is forced in such a manner as to produce AMO-type fluctuations similar to those in the observational record and have determined how reliable a temperature proxy would need to be in order to record such fluctuations with an acceptable signal-tonoise ratio. It is shown that many of the currently employed (surface and subsurface) temperature proxies should be capable of capturing AMO variability, providing that appropriate sampling locations are chosen and an annual resolution can be achieved. At lower resolutions, for example decadal, the sediment-based proxies carry too large an error to provide reliable reconstructions of the temperature anomalies associated with the AMO.

\section{Model and experimental design}

The University of Victoria Earth System Climate Model (UVic ESCM version 2.8, Weaver et al., 2001) consists of a two-dimensional atmospheric energy-moisture balance model (Fanning and Weaver, 1996) coupled to a dynamicthermodynamic sea ice model (Weaver et al., 2001) and a three-dimensional ocean model (MOM2, Pacanowski, 1995). The model is forced with seasonally-varying insolation at the top of the atmosphere and prescribed monthly wind stresses (Kalnay et al., 1996). The horizontal resolution of the model is $1.8^{\circ}$ in latitude and $3.6^{\circ}$ in longitude, whilst the ocean component is constructed with 19 vertical levels, varying in thickness from $50 \mathrm{~m}$ at the surface to $500 \mathrm{~m}$ at the base.

Unlike more complex models, the UVic ESCM does not generate AMO-type multidecadal behavior as part of its internal variability (Stouffer et al., 2006). Instead, we have adopted a forcing concept similar to that of Zhang and Delworth (2006) and have applied a pattern of anomalous heat fluxes to the surface of the Atlantic to mimic the observed structure of the AMO over the 20th century. The advantages of such an approach are twofold: first, the spatial pattern, amplitude and frequency content of the AMO can be controlled. Second, any anomalies in the model with respect to a control run can be unequivocally attributed to the AMO-type forcing.

We adopted the following definition of the AMO index: the low-pass filtered (10 year moving average, Enfield et al., 2001) spatial average of detrended mean SST anomalies within the North Atlantic. The annual AMO index was first calculated using the monthly version of the HadISST sea surface temperature component (Rayner et al., 2003). A spatial pattern of the sea surface temperature anomalies associated with the AMO was then obtained by calculating the difference, $\delta \operatorname{SST}(\mathrm{K})$, in detrended SST between 1941 1960 CE (observed positive AMO phase) and 1971-1990 CE (observed negative AMO phase) as a function of location over the Atlantic. The map of $\delta \mathrm{SST}(\mathrm{K})$ was then converted in anomalous heat fluxes, $\delta Q\left(\mathrm{~W} / \mathrm{m}^{2}\right)$, by multiplication with a coupling coefficient of $30 \mathrm{~W} / \mathrm{m}^{2} / \mathrm{K}$ (Haney, 1971). Finally, a small constant was subtracted from $\delta Q$ to ensure that its spatial integral was zero (Zhang and Delworth, 2006).

The anomalous heat fluxes form a basin scale dipole about the equator and thus are suitable to induce northward heat transport in the Atlantic, mimicking changes in the AMOC (Zhang and Delworth, 2006). At a given time, $t$, when the AMO index is $\operatorname{AMO}(t)$, the anomalous heat flux, $Q(t)$, applied to the surface of the Atlantic in the UVic ESCM was defined as $Q(t)=\delta Q \times(\mathrm{AMO}(t) / \delta \mathrm{AMO})$. Here $\delta \mathrm{AMO}$ was a scaling factor selected in order that the amplitude of the AMO index generated in the model was similar to that in the instrumental record. On the basis of a number of trial runs, $\delta$ AMO was determined to be $\sim 0.18 \mathrm{~K}$.

A 2000-year integration was employed to bring the UVic ESCM into equilibrium with boundary conditions and insolation forcing appropriate for $1850 \mathrm{CE}$. The anomalous heat flux was then introduced with a repeating pattern of the AMO index following the time series obtained from the data of Rayner et al. (2003) before low-pass filtering. After the run was completed, the temperature values for the final sequence of index values were extracted and anomalies were calculated with respect to a control run. The modelled AMO index was then obtained from the temperature anomalies calculated for the upper layer of the ocean.

\section{Results and discussion}

Figure 1 shows the results of the modelled AMO index compared to the observed index values obtained from the SST data of Rayner et al. (2003). The unfiltered indices obtained from the observations are more variable than those produced in the model. The same phenomenon appeared in the unfiltered index values of Zhang and Delworth (2006), who modelled the AMO using a similar forcing approach. It is assumed that the smoother model values are a product of the redistribution of the heat introduced by the forcing. After 

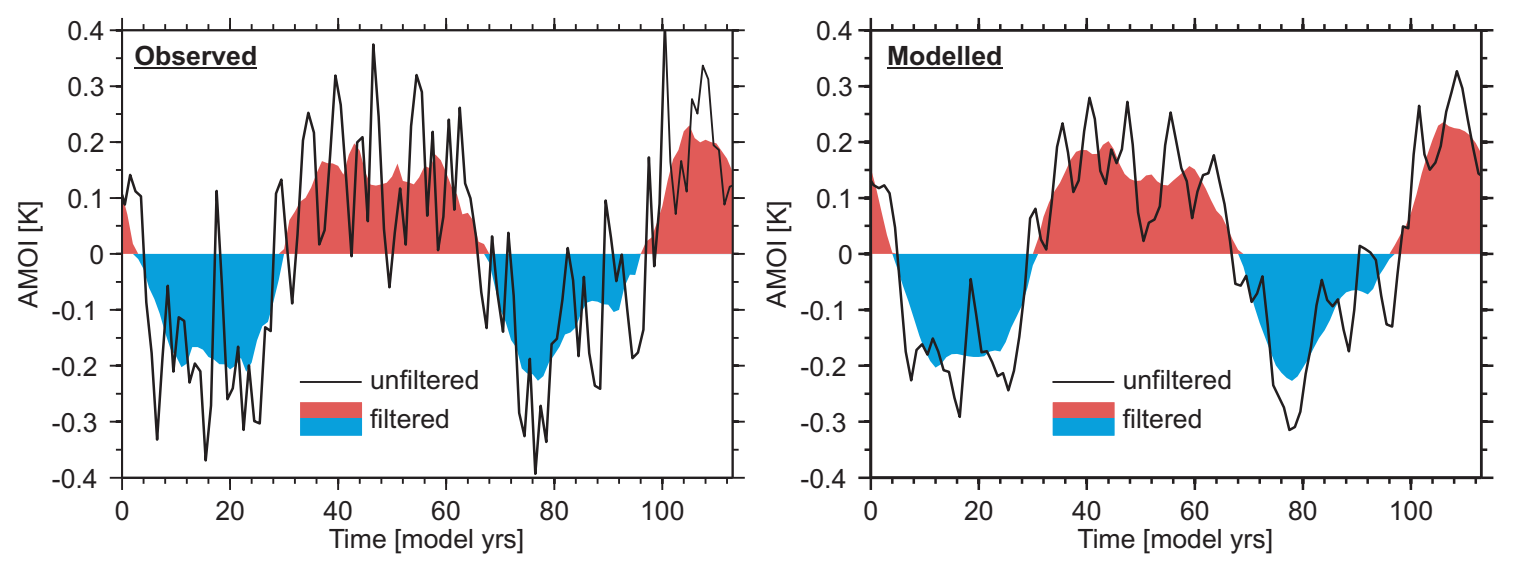

Fig. 1. Observed and modelled AMO index, pre- (lines) and post- (shaded) low-pass filtering (10 year moving average). Positive and negative phases of the AMO are shown by red and blue shading, respectively.

filtering (10 year moving average) to isolate the multidecadal variability, the observed and modelled indices display consistent phases and amplitudes.

The influence of the anomalous heat flux on the strength of the AMOC was quantified by performing a complex (time domain) empirical orthogonal function analysis (CEOF, von Storch and Zwiers, 1999) of the Atlantic annual mean meridional overturning streamfunction over time. The advantage of CEOF analysis is that individual components can contain contributions with different phases. Thus it is possible to capture the AMO-type variability throughout the streamfunction even though different locations may not be in phase. The AMOC in the control run had a maximum value of $\sim 22 \mathrm{~Sv}$, which showed very little variability over time $(<0.04 \mathrm{~Sv})$, Fig. 2. In contrast, when the AMO-type forcing was introduced, the AMOC displayed variation over a large area, with the leading CEOF (explaining $~ 97 \%$ of the total variance) having a maximum amplitude of $\sim 1.5 \mathrm{~Sv}$, Fig. 2 .

Previous modelling studies have proposed that the AMOC plays a controlling role in modulating the strength of the AMO (Vellinga and Wu, 2004; Knight et al., 2005), whilst in our simulations the introduced anomalous heat flux drives changes in the AMOC. This relationship is demonstrated in the lowermost panel of Fig. 2, when the introduced anomalous heat flux warms the surface of the North Atlantic, stratification of the water column increases and after $\sim 10$ years the vigor of the AMOC is reduced. Subsequently, when the forcing cools the surface of the North Atlantic, the strength of the AMOC increases after a short delay. This role reversal introduced by the model forcing does not allow us to comment on the nature of AMO forcing in reality, but does help to demonstrate the important relationship between overturning and heat in the upper ocean.

As expected the UVic ESCM does redistribute the anomalous heat introduced by $Q$. Thus the spatial distribution of the SST anomalies resulting from the AMO-type forcing in the UVic ESCM is different to the instrumental record (which was the basis of the $\delta$ SST forcing pattern). The map of $\delta$ SST from the instrumental record and an equivalent determination (positive phase minus negative phase) of the AMO $\delta$ SST pattern in the model run are shown in Fig. 3. In comparison to the instrumental record, the SST pattern in the model run shows an enhanced bipolar structure about the equator, with positive anomalies concentrated too far north and not extending far enough to the south. It would appear most likely that this phenomenon is a product of the variations induced in the AMOC by the anomalous heat flux (Broecker, 1998; Stocker, 1998; Stocker and Johnsen, 2003). Such a northerly-biased distribution of SST anomalies is typical of the AMO-type patterns generated in a number of more complex models, which produce multidecadal AMOC fluctuations as part of their internal variability (Delworth and Mann, 2000; Knight et al., 2005). The key aspect for this study, however, is that although the spatial distributions differ to some extent, the magnitude of the SST anomalies are similar in both the instrumental record and the AMO-type forced UVic ESCM. It is also important to bear in mind that the spatial SST pattern of the AMO obtained from the instrument record is based on a single oscillation and may therefore not be representative of long-term behavior.

Of specific interest to this study is the amplitude of the temperature anomalies generated in the surface and deeper layers of the ocean as a result of the anomalous heat flux forcing. Such information will allow us to address the question if proxy studies based on, for example, the composition of foraminiferal tests or the growth-rate/composition of corals are able to reconstruct the kind of temperature oscillations expected as part of AMO variability. More specifically, are such proxies sufficiently accurate and of a high enough temporal resolution to reconstruct the temperature variations associated with past AMO variability? 


\subsection{Statistical framework}

It is common for the quality of temperature proxy calibration studies to be assessed using the standard error of estimation (for examples see Saenger et al., 2009; Lear et al., 2002; Marchitto et al., 2007; Bamberg et al., 2010). If $T$ is the observed temperature, $\hat{T}$ is the temperature predicted by the estimated calibration relationship and $N$ is the number of samples employed in the calibration, the standard error of estimation, $s$, is given by (Taylor, 1997):

$s=\sqrt{\frac{\sum_{i=1}^{N}\left(T_{i}-\hat{T}_{i}\right)^{2}}{N-2}} \quad$ where $\quad i=1, \ldots, N$.

The minimum achievable standard error, $S_{\mathrm{E}}$, on a temperature prediction obtained from a new observation, i.e. applying the derived calibration to a new sample, is given by (Devore, 2008):

$S_{\mathrm{E}}=s \sqrt{1+\frac{1}{N}}$.

A single realization of the possible error on the calibrated value can then be found by multiplying $S_{\mathrm{E}}$ by a random number drawn from Student's $t$ distribution with $N$-2 degrees of freedom (Davies and Goldsmith, 1984).

To assess the ability of a given proxy in a given location to produce a reliable reconstruction of temperature changes resulting from the AMO, we performed the following analysis, which required some simplifying assumptions to make the results generally applicable. If the calibration of a proxy is based on a sufficiently high number of data points, then $S_{\mathrm{E}} \approx s$ and Student's $t$ distribution approximates a standardized normal distribution. Therefore, the temperature uncertainty (effectively noise) in new predictions obtained from the estimated calibration equation can be assumed to be normally distributed with a mean of 0 and standard deviation equal to $s$. Thus, under an assumption of independent and identically distributed error values, it is possible to simulate the noise that can be expected to be included in the estimated temperature values obtained from a calibrated proxy. As stated above, it is necessary to incorporate simplifying assumptions in this study in order to compare a number of different calibrated proxies. For individual cases, however, the study specific value of $N$ could be employed in Eq. 2 and the standard error on a new prediction could be calculated separately for each new sample rather than assuming the minimum achievable error (Devore, 2008).

For the case of a reconstructed temperature record with a temporal resolution of $\delta t$ and low-pass filtered with a $\tau$ year moving average in the same manner as the AMO index (thus $\delta t$ must be $\leqslant \tau$ years), the variance of the noise component, $\sigma_{n}^{2}$, will be:

$\sigma_{n}^{2}=\frac{\delta t \times s^{2}}{\tau}$
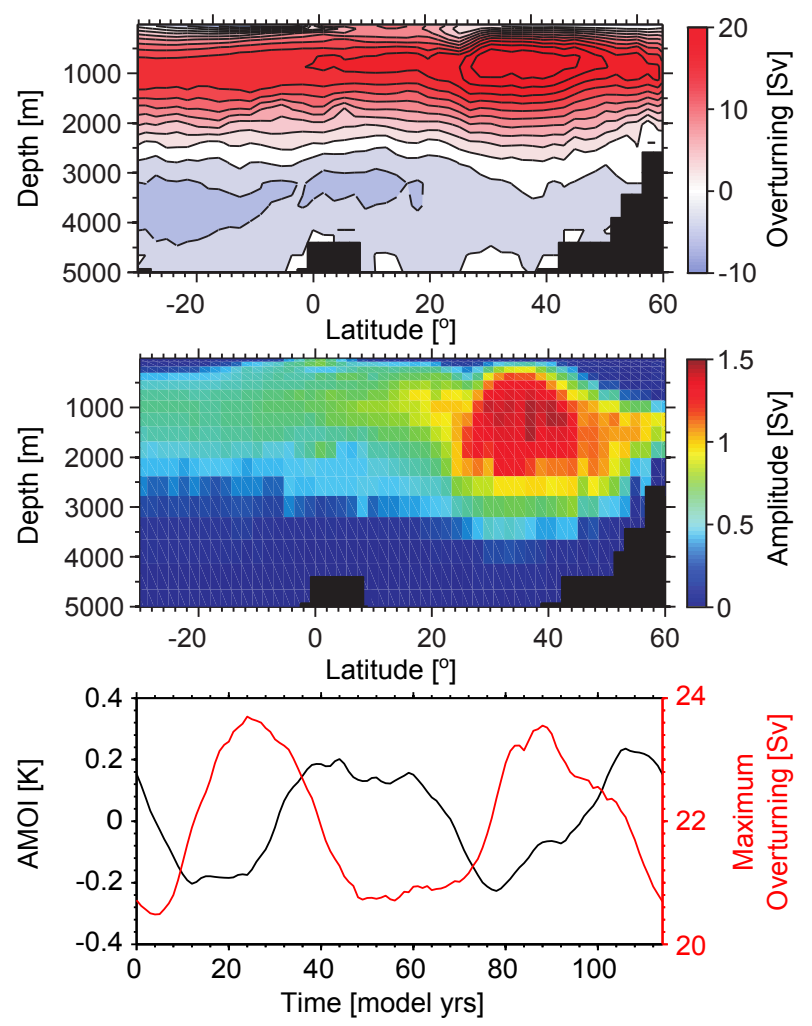

Fig. 2. (Top) Annual mean meridional overturning streamfunction for the Atlantic obtained from the control run with no AMO-like forcing. (Middle) Amplitude of the leading complex empirical orthogonal function, showing the amplitude of the variability induced in the AMOC by the AMO-like forcing. (Bottom) Variations in modelled AMO index and the maximum of the meridional overturning streamfunction for the Atlantic resulting from the AMO-like forcing.

If the variance, $\sigma_{T}^{2}$, of the noise free low-pass filtered temperature anomalies obtained from the model for a given location is compared to the expected variance of the smoothed noise inherent in a given proxy-calibration, a simple expression for the signal-to-noise ratio, SNR, of the potential proxy reconstruction can be determined:

$\mathrm{SNR}=\frac{\sigma_{T}^{2}}{\sigma_{n}^{2}}$

This means if $s$ is known, the SNR of the low-pass filtered temperature anomaly record can be determined, or alternatively the magnitude of $s$ required to achieve a given SNR can be assessed. We have adopted the latter approach and work under the assumption that the minimum possible value of SNR indicative of an interpretable reconstruction is $\mathrm{SNR}=1$, i.e. the noise and the true temperature variation make equal contributions to the final reconstruction.

Figure 4 shows the maximum value of the standard error of estimation, $s^{\max }$, which can be tolerated in a proxy calibration in order that the 10 year moving average 

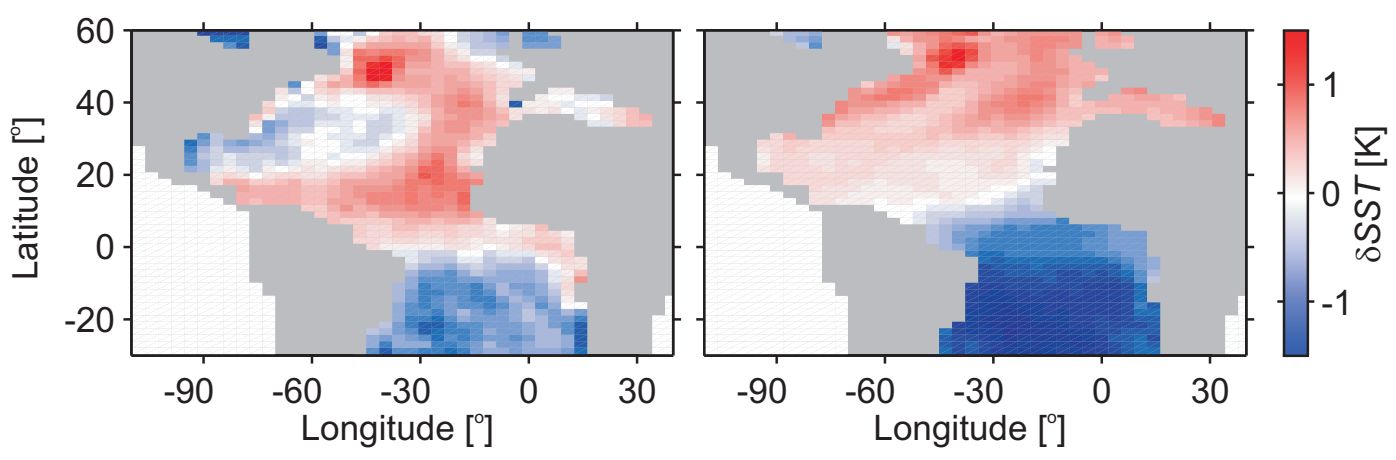

Fig. 3. (Left) Anomalous SST pattern associated with the AMO component of the instrumental record. The temperature anomalies during a negative phase of the AMO were subtracted from those of a positive phase to yield the difference map, $\delta$ SST. (Right) Anomalous SST pattern obtained from the difference of positive and negative AMO phases in the UVic ESCM.

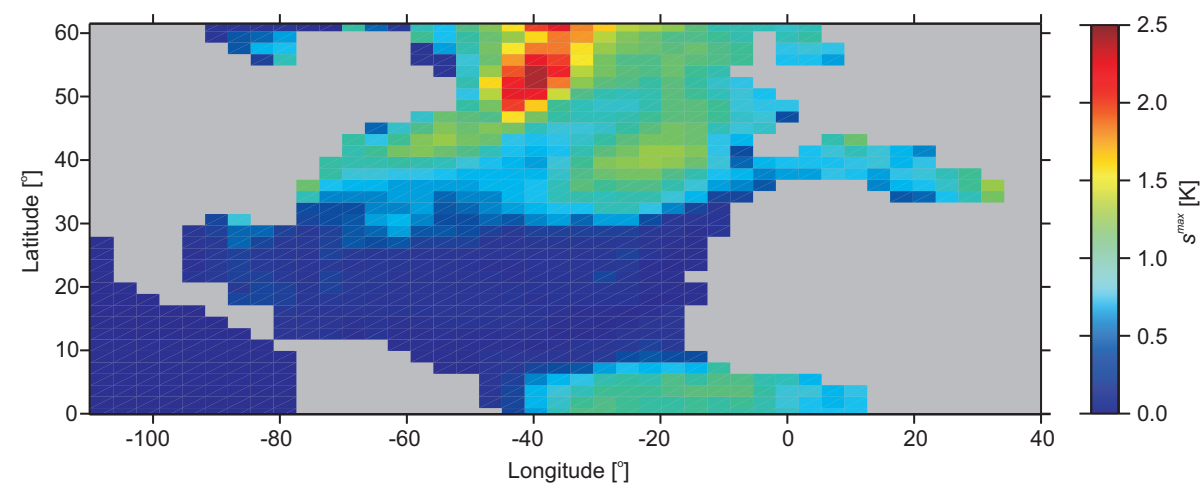

Fig. 4. The maximum allowable standard error of estimation, $s^{\max }$, in a calibrated SST proxy if the temperature variability attributable to the AMO is to be reconstructed with a SNR $\geqslant 1$. It is assumed that the temporal resolution of the proxy data is 1 year and the estimated values of $s^{\max }$ represent the best case scenario. If the temporal resolution was decreased then $s^{\text {max }}$ would also decrease.

filtered reconstructed temperature variability resulting from the AMO-type forcing has a SNR $\geqslant 1$. Given the assumptions discussed above, this example represents the best case scenario. It is based on the smallest possible error distribution for the predictions (i.e. high $N$ ) and assumes an annual resolution. Records with a lower resolution or which exhibit disturbance due to processes such as bioturbation can be expected to have a reduced $\sigma_{T}^{2}$, whilst $s$ is independent of such factors. Thus, such records would be expected to be characterized by lower SNRs and the values of the tolerable $s^{\max }$ in Fig. 4 would be lower (this will be discussed in more detail below).

A clear pattern emerges in Fig. 4 with surface proxies requiring a low standard error between $0-30^{\circ} \mathrm{N}$, whilst higher standard errors are tolerable north of $30^{\circ} \mathrm{N}$. This pattern follows the general spatial structure of SST variations associated with the AMO extracted from the instrumental record by Sutton and Hodson (2005) but, as mentioned above, contains an enhanced bipolar structure. Low values of $s^{\max }$ between $0-30^{\circ} \mathrm{N}$ do not imply that the reconstruction of multidecadal temperature variations possibly attributable to the AMO are unfeasible in the low-latitude North Atlantic, but simply the uncertainty associated with the proxy calibration must be sufficiently low. Saenger et al. (2009) reconstructed multidecadal SST variations for the region around the Bahamas using a coral-based SST proxy. The reconstruction had an annual resolution with an estimated $s \approx 0.3 \mathrm{~K}$, in comparison, the corresponding $s^{\max }$ in Fig. 4 for the study location is $\sim 0.4 \mathrm{~K}$, indicating that the SNR of the Saenger et al. (2009) record could be $>1$ providing an adequate number of samples were included in the calibration to fulfill the assumptions given above (a collection of the discussed proxies and their quoted standard errors of estimation are given in Table 1).

North of $30^{\circ} \mathrm{N}$ the value of $s^{\max }$ increases, particularly within the northward and southward flowing branches of the subtropical gyre. In particular, maximum values of $s^{\max }$ are found in the southern portion of the subpolar gyre (SPG), supporting studies which have demonstrated a link between the AMO index and the strength of the SPG (Zhang, 2008). The elevated values of $s^{\max }$ in these regions suggest that a number of existing paleothermometers should be capable of recording the temperature variations associated with the AMO in the mid-latitude North Atlantic. 
Table 1. Collection of the seawater temperature proxies discussed in this work and their standard errors of estimation $(s)$.

\begin{tabular}{|c|c|c|c|}
\hline Parameter & Proxy for & $s$ & References \\
\hline \multirow[t]{3}{*}{$\mathrm{Mg} / \mathrm{Ca}$ (Planktonic) } & SST & $\sim 1 \mathrm{~K}$ & Lea et al. (1999) \\
\hline & & & Dekens et al. (2002) \\
\hline & & & Anand et al. (2003) \\
\hline \multirow[t]{3}{*}{$\mathrm{Mg} / \mathrm{Ca}$ (Benthic) } & seawater temperature & $1.7 \mathrm{~K}$ & Lear et al. (2002) \\
\hline & & $2.4 \mathrm{~K}$ & Marchitto et al. (2007) \\
\hline & & $0.7 \mathrm{~K}$ & Bamberg et al. (2010) \\
\hline $\mathrm{TEX}_{86}$ & upper mixed layer temperature & $1.7 \mathrm{~K}$ & Kim et al. (2008) \\
\hline$U_{37}^{K^{\prime}}$ & SST & $1.2 \mathrm{~K}$ & Conte et al. (2006) \\
\hline Coral growth anomaly & SST anomaly & $\sim 0.3 \mathrm{~K}$ & Saenger et al. (2009) \\
\hline
\end{tabular}

The $\mathrm{Mg} / \mathrm{Ca}$ ratio of the tests of planktonic foraminifers has been shown to be (at least partially) a function of calcification temperature (Lea, 1999). A wide array of speciesspecific and species-nonspecific calibrations indicate that $s$ for Mg/Ca based estimates of SST is $\sim 1 \mathrm{~K}$ (Lea et al., 1999; Dekens et al., 2002; Anand et al., 2003). Alternative ocean paleothermometers such as $\mathrm{TEX}_{86}$ (thought to reflect the annual mean temperatures of the upper mixed layer) and $U_{37}^{K^{\prime}}$ (a SST proxy) have quoted $s$ values of $1.7 \mathrm{~K}$ (Kim et al., 2008) and $1.2 \mathrm{~K}$ (Conte et al., 2006), respectively. The magnitude of these errors suggest that providing sufficiently highresolution sediment archives exist (a point discussed below), such temperature proxies could be applicable at appropriately chosen locations, but not throughout the entire Atlantic.

The subsurface fingerprint of the AMO and the values of $s^{\max }$ that will allow its reconstruction in proxy studies are of particular interest in this investigation, Fig. 5. The temperature signature of the AMO reaches a depth of $\sim 1400 \mathrm{~m}$ but the values of $s^{\max }$ are low. Determined standard errors for candidate proxies suggest that subsurface temperature variations resulting from the AMO could only be reconstructed with relatively low SNR values. For example, benthic foraminiferal $\mathrm{Mg} / \mathrm{Ca}$ based temperature estimates have quoted $s$ values of $1.7 \mathrm{~K}$ (Lear et al., 2002), $2.4 \mathrm{~K}$ (Marchitto et al., 2007) and 0.7 K (Bamberg et al., 2010), suggesting that only the latter case would be capable of producing reconstructions with SNR $>1$.

\subsection{Limiting factors: sedimentation rate and bioturbation}

As discussed above, a number of the considered seawater temperature proxies appear to be sufficiently accurate to record the signature of the AMO providing they can achieve an annual resolution. In the open ocean, such resolutions are highly unlikely and it is necessary to consider the effects of low sedimentation rates and processes such as bioturbation, both of which act to smooth the recorded temperature signal. A demonstration of this problem can be given using the results presented in Figs. 4 and 5.
The mean annual temperature anomaly records produced by the UVic ESCM were smoothed with a 10 year moving average in order make them compatible with the definition of the AMO index. These filtered data can also be used to represent a record with a reduced sedimentation rate (and/or increased bioturbation) acting to smooth out the high frequency variation, leaving only the decadal and multidecadal components. Whilst such processes smooth the recorded signal, they have no influence on the noise resulting from the uncertainty in the proxy calibration.

Figures 4 and 5 were produced by considering a noise component smoothed according to Eq. (3), where $\delta t=1 \mathrm{yr}$ and $\tau=10 \mathrm{yrs}$. For the case of a temperature signal smoothed by the accumulation rate / bioturbation and a non-smoothed noise component, the values of $s^{\max }$ presented in Figs. 4 and 5 need to be divided by a factor of $\sqrt{10}$. For example, the maximum value of $s^{\max }$ in Fig. 4 is $\sim 2.5 \mathrm{~K}$ in the subpolar gyre; when considering a non-filtered sediment record with decadal resolution this value of $s^{\max }$ becomes $2.5 / \sqrt{10}=0.79 \mathrm{~K}$. Similarly, the maximum value of $s^{\max }$ in Fig. 5 is $\sim 1.7 \mathrm{~K}$, which becomes $1.7 / \sqrt{10}=0.54 \mathrm{~K}$. This is a particularly demonstrative result showing that the majority of the considered sediment-based proxies would be capable of recording the AMO if annual resolution could be achieved. However, with only decadal resolution (which is still optimistic for the open ocean), none of the proxies would yield a $\mathrm{SNR} \geqslant 1$.

Shifts in the period of the AMO will also play an important role in determining the ability of a given proxy to faithfully reconstruct the associated temperature variations. Such changes in the timescale of the AMO were detected in the coral-based record of Saenger et al. (2009) and appear to be a real component of the AMO's natural variability. If the strength of the seawater temperature variations related to AMO variability are approximately sinusoidal and their amplitude is independent of their period, their variance will be constant (since the variance of a sinusoid depends only on its amplitude). However, as the period of the AMO decreases it will be more heavily smoothed by the 10 year moving average filter. For example, Delworth and Mann (2000) estimate 


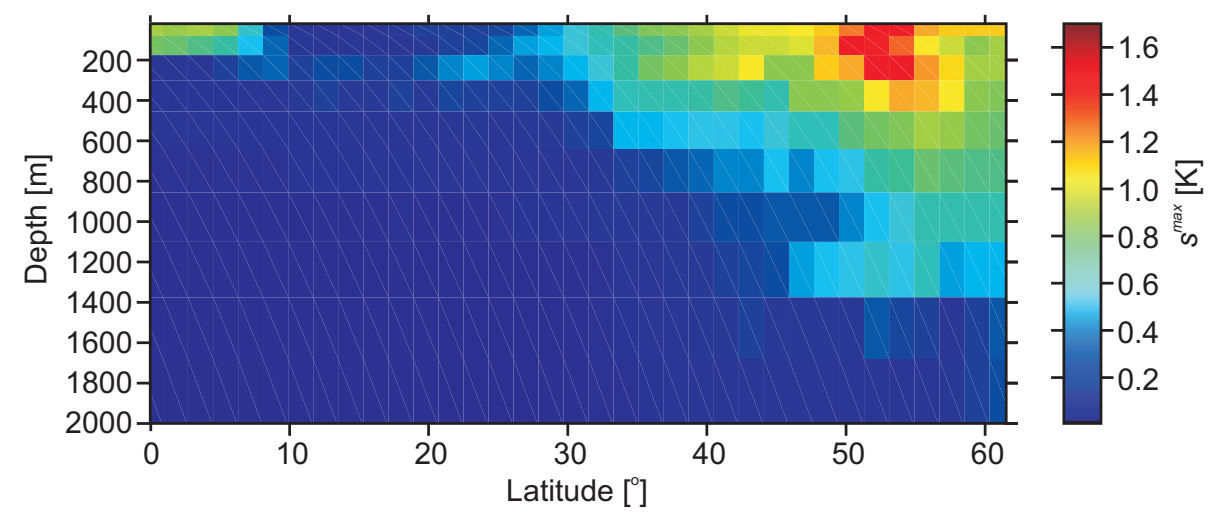

Fig. 5. Zonally averaged $s^{\max }$ in a calibrated temperature proxy if the temperature variability attributable to the AMO is to be reconstructed for annually resolved data with a $\mathrm{SNR} \geqslant 1$.

the period of the AMO to be 30-80 years, but a sinusoid with $\delta t=1$ and a period of 30 years will lose $\sim 30 \%$ of its variance once filtered with a 10 year moving average. This means that as the period of the AMO decreases the numerator in Eq. 4 will be reduced, thus $s^{\max }$ must also be reduced to maintain a $\mathrm{SNR}>1$. This situation is compounded for sediment-based proxies, which even if they can achieve a decadal resolution will only have 4 data points representing each cycle of a 30 year AMO.

\section{Conclusions}

Our model and subsequent statistical analysis reveal that under a best-case scenario, existing ocean paleothermometers may be capable of recovering interpretable records of the temperature variations in the North Atlantic associated with the past activity of the AMO. Whilst such a scenario appears to be appropriate for coral-based reconstructions, sediment records have a lower resolution and may have been disrupted by processes such as bioturbation. For the case where sediment records have a decadal resolution, the quoted accuracy of proxies such as $\mathrm{Mg} / \mathrm{Ca}, \mathrm{TEX}_{86}$ and $U_{37}^{K^{\prime}}$ suggests that they would yield reconstructions of the temperature anomalies resulting from the AMO with SNRs less than 1.

A simple strategy when the characteristics of a proxy record are sub-optimal would be to filter the reconstructed temperatures at longer periods, thus decreasing the noise contribution. Such an approach will of course reduce comparability with the AMO characteristics obtained from the observational record, but may represent the only opportunity to recover some of the useful information buried within a relatively high noise component. It is, however, important to remember that the form of the final signal will be controlled by the specific filter design and thus must be taken into consideration when interpreting and comparing signals.

It would appear that climate models have an invaluable role to play in estimating the potential SNR with which dif- ferent proxies could be expected to reconstruct certain modes of variability. Such information is essential if the quality of proxy records is to be assessed objectively, but it should always be kept in mind that the results will be dependent on the model. Finally, the presented approach is not limited to the AMO and seawater temperature, but can potentially be applied to a wide variety of calibrated proxies both in and outside the marine realm.

Acknowledgements. We are grateful to two anonymous reviewers, whose constructive comments helped to improve the manuscript. This work was funded as part of the DFG Priority Programme 1266 "Integrated Analysis of Interglacial Climate Dynamics (INTERDYNAMIC)" and DFG-Research Center/Cluster of Excellence "The Ocean in the Earth System".

Edited by: G. M. Ganssen

\section{References}

Anand, P., Elderfield, H., and Conte, M. H.: Calibration of $\mathrm{Mg} / \mathrm{Ca}$ thermometry in planktonic foraminifera from a sediment trap time series, Paleoceanography, 18, 1050, doi:10.1029/2002PA000846, 2003.

Bamberg, A., Rosenthal, Y., Paul, A., Heslop, D., Mulitza, S., Rühlemann, C., and Schulz, M.: Reduced North Atlantic Central Water formation in response to early Holocene ice-sheet melting, Geophys. Res. Lett., 37, L17705, doi:10.1029/2010GL043878, 2010.

Black, D. E., Abahazi, M. A., Thunell, R. C., Kaplen, A., Tappa, E. J., and Peterson, L. C.: An 8-century tropical Atlantic SST record from the Cariaco Basin: Baseline variability, twentiethcentury warming, and Atlantic hurricane frequency, Paleoceanography, 22, PA4202, doi:10.1029/2007PA001427, 2007.

Broecker, W. S.: Paleocean circulation during the last deglaciation: A bipolar seesaw?, Paleoceanography, 13, 119-121, 1998.

Conte, M. H., Sicre, M.-A., Rühlemann, C., Weber, J. C., Schulte, S., Schulz-Bull, D., and Blanz, T.: Global temperature calibration of the alkenone unsaturation index $\left(U_{37}^{K^{\prime}}\right)$ in surface wa- 
ters and comparison with surface sediments, Geochem. Geophy. Geosy., 7, Q02005, doi:10.1029/2005GC001054, 2006.

Davies, O. L. and Goldsmith, P. L.: Statistical methods in research and production, Longman, 4 edn., 1984.

Dekens, P. S., Lea, D. W., Pak, D. K., and Spero, H. J.: Core top calibration of $\mathrm{Mg} / \mathrm{Ca}$ in tropical foraminifera: refining paleotemperature estimation, Geochem. Geophy. Geosy., 3, 1022, doi:10.1029/2001GC000200, 2002.

Delworth, T. L. and Mann, M. E.: Observed and simulated multidecadal variability in the Northern Hemisphere, Clim. Dynam., 16, 661-676, 2000.

Delworth, T. L., Zhang, R., and Mann, M. E.: Ocean Circulation: Mechanisms and Impacts, vol. 173 of Geophysical Monograph Series, chap. Decadal to Centennial Variability of the Atlantic From Observations and Models, 131-148, AGU, 2007.

Devore, J. L.: Probability and Statistics for Engineering and the Sciences, Duxbury Press, 7 edn., 2008.

Enfield, D. B., Mestas-Nuñez, A. M., and Trimble, P. J.: The Atlantic multidecadal oscillation and its relation to rainfall and river flows in the continental U.S., Geophys. Res. Lett., 28(10), 20772080, 2001.

Fanning, A. F. and Weaver, A. J.: An atmospheric energy moisturebalance model: climatology, interpentadal climate change and coupling to an OGCM, J. Geophys. Res., 101, 15111-15128, 1996.

Gray, S. T., Graumlich, L. J., Betancourt, J. L., and Pederson, G. T.: A tree-ring based reconstruction of the Atlantic Multidecadal Oscillation since 1567 A.D., Geophys. Res. Lett., 31, L12205, doi:10.1029/2004GL019932, 2004.

Haney, R. L.: Surface thermal boundary condition for ocean circulation models, J. Phys. Oceanogr., 1, 241-248, 1971.

Kalnay, E., Kanamitsu, M., Kistler, R., Collins, W., Deaven, D., Gandin, L., Iredell, M., Saha, S., White, G., Woollen, J., Zhu, Y., Leetmaa, A., Reynolds, R., Chelliah, M., Ebisuzaki, W., Higgins, W., Janowiak, J., Mo, K., Ropelewski, C., Wang, J., Jenne, R., and Joseph, D.: The NCEP/NCAR 40-Year Reanalysis Project, B. Am. Meteorol. Soc., 77(3), 437-471, 1996.

Kilbourne, K. H., Quinn, T. M., Webb, R., Guilderson, T., Nyberg, J., and Winter, A.: Paleoclimate proxy perspective on Caribbean climate since the year 1751: Evidence of cooler temperatures and multidecadal variability, Paleoceanography, 23, PA3220, doi:10.1029/2008PA001598, 2008.

Kim, J.-H., Schouten, S., Hopmans, E. C., Donner, B., and Damsté, J. S. S.: Global sediment core-top calibration of the $\mathrm{TEX}_{86}$ paleothermometer in the ocean, Geochim. Cosmochim. Ac., 72, 1154-1173, doi:10.1016/j.gca.2007.12.010, 2008.

Knight, J. R., Allan, R. J., Folland, C. K., Vellinga, M., and Mann, M. E.: A signiture of persistant natural thermohaline circulation cycles in observed climate, Geophys. Res. Lett., 32, L20708, doi:10.1029/2005GL024233, 2005.

Kuhnert, H., Pätzold, J., Schnetger, B., and Wefer, G.: Sea-surface temperature variability in the 16th century at Bermuda inferred from coral records, Palaeogeogr. Palaeocl., 179, 159-171, 2002.

Lea, D. W.: Modern Foraminifera, chap. Trace elements in foraminiferal calcite, 259-277, Kluwer Academic Publishers, 1999.

Lea, D. W., Mashiotta, T. A., and Spero, H. J.: Controls on magnesium and strontium uptake in planktonic foraminifera determined by live culturing, Geochim. Cosmochim. Ac., 63(16), 2369-
2379, 1999.

Lear, C. H., Rosenthal, Y., and Slowey, N.: Benthic foraminiferal $\mathrm{Mg} / \mathrm{Ca}$-paleothermometry: a revised core-top calibration, Geochim. Cosmochim. Ac., 66(19), 3375-3387, doi:10.1016/S0016-7037(02)00941-9, 2002.

Mann, M. E. and Park, J.: Global scale modes of surface temperature variability on interannual to century scales, J. Geophys. Res., 99, 25819-25833, 1994.

Marchitto, T. M., Bryan, S. P., Curry, W. B., and McCorkle, D. C.: $\mathrm{Mg} / \mathrm{Ca}$ temperature calibration for the benthic foraminifer Cibicidoides pachyderma, Paleoceanography, 22, PA1203, doi:10.1029/2006PA001287, 2007.

Pacanowski, R. C.: MOM 2 Documentation, User's Guide and Reference Manual, Technical report, GFDL Ocean Group, NOAA, GFDL, Princeton, New Jersey, 1995.

Rayner, N. A., Parker, D. E., Horton, E. B., Folland, C. K., Alexander, L. V., Rowell, D. P., Kent, E. C., and Kaplan, A.: Global analyses of sea surface temperature, sea ice, and night marine air temperature since the late nineteenth century, J. Geophys. Res., 108(D14), 4407, doi:10.1029/2002JD002670, 2003.

Saenger, C., Cohen, A. L., Oppo, D. W., Halley, R. B., and Carilli, J. E.: Surface-temperature trends and variability in the lowlatitude North Atlantic since 1552, Nat. Geosci., 2, 492-495, doi:10.1038/NGEO552, 2009.

Schlesinger, M. E. and Ramankutty, N.: An oscillation in the global climate system of period 65-70 years, Nature, 367, 723-726, 1994.

Shanahan, T. M., Overpeck, J. T., Anchukaitis, K. J., Beck, J. W., Cole, J. E., Dettman, D. L., Peck, J. A., Scholz, C. A., and King, J. W.: Atlantic Forcing of Persistant Drought in West Africa, Science, 324, 377-380, 2009.

Sicre, M.-A., Jacob, J., Ezat, U., Rousse, S., Kissel, C., Yiou, P., Eiríksson, J., Knudsen, K. L., Jansen, E., and Turon, J.-L.: Decadal variability of sea surface temperatures off North Iceland over the last 2000 years, Earth Planet. Sc. Lett., 268, 137-142, doi:10.1016/j.eps1.2008.01.011, 2008.

Stocker, T. F.: The seesaw effect, Science, 282, 61-62, 1998.

Stocker, T. F. and Johnsen, S. J.: A minimum thermodynamic model for the bipolar seesaw, Paleoceanography, 18(4), 1087, doi:10.1029/2003PA000920, 2003.

Stouffer, R. J., J. Yin, J. M. G., Dixon, K. W., Spelman, M. J., Hurlin, W., Weaver, A. J., Eby, M., Flato, G. M., Hasumi, H., Hu, A., Jungclaus, J. H., Kamenkovich, I., Levermann, A., Montoya, M., Murakami, S., Nawrath, S., Oka, A., Peltier, W. R., Robitaille, D. Y., Sokolov, A., Vettoretti, G., and Weber, S. L.: Investigating the causes of the response of the thermohaline circulation to past and future climate changes, J. Clim., 19, 13651387, 2006.

Sutton, R. T. and Hodson, D. L. R.: Atlantic ocean forcing of North American and European summer climate, Science, 309, 115118, doi:10.1126/science.1109496, 2005.

Taylor, J. R.: Error analysis: The study of uncertainties in physical measurements, University Science Books, 2 edn., 1997.

Vellinga, M. and Wu, P.: Low-latitude freshwater influence on centennial variability of the Atlantic thermohaline circulation, J. Clim., 17, 4498-4511, 2004.

von Storch, H. and Zwiers, F. W.: Statistical analysis in climate research, 494 pp., Cambridge University Press, 1999.

Weaver, A. J., Eby, M., Wiebe, E. C., Bitz, C. M., Duffy, P. B., 
Ewen, T. L., Fanning, A. F., Holland, M. M., MacFadyen, A., Matthews, H. D., Meissner, K. J., Saenko, O., Schmittner, A., Wang, H., and Yoshimori, M.: The UVic Earth System Climate Model: Model description, climatology and application to past, present and future climates, Atmos. Ocean, 39, 361-428, 2001.
Zhang, R.: Coherent surface-subsurface fingerprint of the Atlantic meridional overturning circulation, Geophys. Res. Lett., 35, L20705, doi:10.1029/2008GL035463, 2008.

Zhang, R. and Delworth, T. L.: Impact of Atlantic multidecadal oscillations on India/Sahel rainfall and Atlantic hurricanes, Geophys. Res. Lett., 33, L17712, doi:10.1029/2006GL026267, 2006. 